\title{
Computed tomography use in a large Italian region: trend analysis 2004-2014 of emergency and outpatient CT examinations in children and adults
}

\author{
Andrea Pola ${ }^{1}$ (D) - Daniela Corbella ${ }^{2}$. Andrea Righini ${ }^{3}$ - Alberto Torresin ${ }^{4} \cdot$ Paola E. Colombo $^{4}$ - Luigi Vismara ${ }^{5}$. \\ Luca Trombetta $^{4}$. Michele Maddalo ${ }^{4}$. Maria Vittoria Introini ${ }^{1}$. Daniela Tinelli ${ }^{4}$ - Laura Strohmenger ${ }^{6}$. \\ Giovanna Garattini ${ }^{6} \cdot$ Angelica Munari $^{6} \cdot$ Fabio Triulzi $^{7}$
}

Received: 24 January 2017 / Revised: 20 November 2017 / Accepted: 29 November 2017

(C) European Society of Radiology 2018

\begin{abstract} focusing on developing age. between 2004-2014 in emergency and outpatient care and assessment of radiation exposure trend. $48 \%$. further investigations.

Key Points

- Literature highlights a remarkable increase in CT use over the last decades.

- The paediatric age had higher exposure to X-ray risk.

- A detailed retrospective analysis of more than 9 million scans was performed.

- Dental, chest, abdominal procedures increased remarkably in 10- to 30-year age range.

- This study raises concern about exposure for teenagers and young adults.
\end{abstract}

Objectives To analyse CT use in recent years in a high-density Italian area ( \pm 10 million inhabitants, including 1 million children),

Methods Retrospective analysis of records from HealthCare IT System, covering $>400$ hospitals and clinics. Description of CT use

Results Over 9 million scans were performed. Emergency procedures showed a global increase of $230 \%$, mainly head examinations. In the global outpatient setting, the annual number of CT scans/person increased $\pm 19 \%$. A moderate increase in CT examinations was observed in the developing age population, while a remarkable increase in dental, chest and abdominal procedures occurred for the 10- to 30-year age range. The increase in mean annual dose/capita in the global patient pool was approximately $42 \%$, increasing from $0.72-1.03 \mathrm{mSv}$. The population rate receiving an annual $\mathrm{CT}$ radiation dose/capita higher than $1 \mathrm{mSv}$ tripled in the 11-year interval, increasing from 16-

Conclusions The remarkable increase in radiation exposure raises a special concern for teenagers and young adults, whose risk tends to be underestimated. The fivefold increase in dental CTs in the younger age groups requires

Electronic supplementary material The online version of this article (https://doi.org/10.1007/s00330-017-5225-x) contains supplementary material, which is available to authorized users.

Andrea Pola

andrea.pola@polimi.it

1 Department of Energy, Politecnico di Milano, via La Masa 34, 20156 Milan, Italy

2 ASL Milano2 Melegnano, ATS Milano Città Metropolitana, Milan, Italy

3 Department of Pediatric Radiology and Neuroradiology, V. Buzzi Children's Hospital, Milan, Italy
4 Department of Medical Physics, ASST Grande Ospedale Metropolitano Niguarda Hospital, Milan, Italy

5 ASST Nord Milano, Sesto San Giovanni, Milan, Italy

6 Department of Biomedical, Surgical and Dental Sciences, Università degli Studi di Milano and Santi Paolo e Carlo Hospital, Milan, Italy

7 Department of Neuroradiology, IRCCS Cà Granda Foundation, Ospedale Maggiore Policlinico, Milan, Italy 
Keywords Regional survey $\cdot$ Computed tomography $\cdot$ Paediatric exposure $\cdot$ Patient dose $\cdot$ Radiation protection

\author{
Abbreviations \\ CBCT Cone beam computed tomography \\ CT Computed tomography \\ DLP Dose length product \\ RHCS Regional Health Care System
}

\section{Introduction}

Data in the literature highlight an increase in the annual number of computed tomography (CT) examinations performed in the last decade in industrialized countries. Some national surveys showed the increasing trend in radiation exposure has nearly doubled in the overall population [1-16].

Although CT examinations still represent only a slight percentage of the total radio-diagnostic procedures, the high radiation dose associated with each CT examination makes such examinations cover more than $70 \%$ of the overall dose from medical practice $[11,13,17,18]$.

Exposure to radiation carries a risk for patients. This risk, in the range of doses involved in radio-diagnostics, is considered directly proportional to the amount of radiation administered to the exposed individual [19-21].

Concern about the spread of CT use has triggered efforts to manage and monitor patient radiation exposure levels associated with this procedure. Recent studies have drawn specific attention to paediatric CT examinations and the higher cancer risk associated with this age group due to the longer life expectation and higher cellular mitogenic activity in this age group [22-29].

More recently, important CT applications have been considered in odontoiatric practice. In 2008, the total number of medical and dental X-ray examinations performed in the UK increased $10 \%$ compared to 1998 [17]. The most frequent examinations in 2008 in Switzerland were conventional and dental radiographies (88\%) [11]. These trends highlighted the increase in the collective dose from dental X-ray examinations, which are increasingly becoming a relevant part of the total medical examinations based on ionizing radiation.

This study proposes a systematic trend analysis of CT use by referring to the examination types and age groups, together with assessment of the per capita effective dose from CT examinations. The study is based on data collected from 2004 to 2014 in Lombardy, an Italian region of 10 million inhabitants. The discussion aims to highlight how the global CT trend, due to all kinds of CT examinations, is related to that of the different CT types and the age groups that, depending on the CT type, require special attention.

\section{Materials and methods}

\section{Data collection}

This retrospective study was performed by processing data collected between 2004 and 2014 by the Regional Health Care System (RHCS). This is a technological platform that systematically collects detailed information related to the patient and procedure anytime a CT examination is performed in the emergency or outpatient setting. No information about inpatient procedure is available.

During an 11-year study period, a total number of about 106 million and 17 million of CT examinations were performed on adult and paediatric patients, respectively. Enrolees from an average resident population of 9.7 million underwent a total of approximately 9.2 million CT examinations at more than 400 facilities.

To have a simple and clear representation of data trends, CT examinations were classified according to the associated body sections and further organized in the following four groups: head (skull, neck, dental, facial and ear); trunk (abdomen, chest); spine; and arthro.

To calculate the number of CT examinations per resident, series from Lombardy residents were extracted from the official archive of the Italian Institute of Statistics (GeoDemo site). The data analysis was performed while considering the entire resident population (age $0-100$ years) and by considering the age group from 0 to 17 years, which corresponds to the paediatric age group in Italy.

\section{Data analysis}

The data analysis was first focused on the total number ofCT scans and on the number of CT scans per resident. Emergency and outpatient cases were processed separately. A detailed analysis was then performed to characterize the numerical variation of CT procedures classified in terms of the different body sections involved.

Paediatric data were analysed according to the same approach adopted for the entire population.

Data extracted from the RHCS allowed for reconstruction of the distribution of the number of CT scans performed at different ages and the time of exposure. Using demographic data by age, the distributions of the number of CT examinations per resident was also calculated.

\section{Per capita effective dose assessment}

Data were used to calculate the per capita effective dose for the whole population due to the main CT examinations (head, abdomen, chest and spine). For this, the results of a CT rate 
analysis were combined with dosimetric data from a multidetector CT study by Palorini et al. [30] that was recently published. This survey reports data collected through questionnaires submitted to Italian medical centres that were mainly selected for their statistical relevance. Each centre provided data according to methodology based on the available technology. The dose length product (DLP) values for different types of examinations, i.e. anatomical sections, are supplied as parametric distributions (gamma functions).

For each examination type (abdomen, chest, head and spine), the annual per capita effective dose distribution $E_{p c}$, exam $(E)$, where $E$ is the effective dose, was calculated by multiplying the DLP distribution taken from the literature by the appropriate DLP-to-dose coefficient [31] and by the annual examination frequency.

The following considerations should be noted:

- DLP values and DLP-to-dose coefficients refer to adults; this approximation affects the calculation performed. More than $75 \%$ of paediatric examinations are typically performed on patients older than 10 years of age, which is an age at which differences with respect to adults decrease in terms of the patient size and protocol. Moreover, the relative weight of the paediatric examination frequency over the total amount is always lower than $4 \%$.

- No scientifically relevant data about the evolution of the dose with respect to the technology are available for the geographic area considered in this study. This could introduce a bias in the adopted DLP values. However, since dosimetric data of Palorini et al. were collected in 2010, a year that is generally in the middle of the study period of this study (2004-2014), the DLP values were assumed as average values.

- A standard patient size was assumed for the DLP-to-dose conversion because the Italian Institute of Statistics does not provide evidence of a significant change in the population body mass index from 2005 to 2014 .

Eventually, the annual per capita effective dose distribution $E_{p c, \text { al }}(E)$ due to all examinations was obtained through the convolution of the $E_{p c \text {,exam }}(E)$. The calculations were only performed for 2004 and 2014 data for comparison aims and trend studies.

\section{Per capita effective dose calculation}

The per capita effective dose calculation procedure is based on the DLP distribution for each type of examination reported by Palorini et al. [30]. To perform the statistical calculations and dose estimation, these distributions, defined as $D_{\text {exam }}(D L P)$, are given in the form of probability functions:

$$
D_{\text {exam }}(D L P)=\frac{D L P^{c-1}}{b^{c}} * \frac{e^{-\frac{D L P}{b}}}{\Gamma(c)}
$$

where $\Gamma(c)$ is the gamma function, a mathematical function used to fit DLP distributions, while $\mathrm{b}$ and $\mathrm{c}$ are parameters that give the proper shape to the distribution.

The annual per capita effective dose distribution due to a single type of examination $E_{p c \text {, exam }}(E)$ can be calculated by scaling the $D_{\text {exam }}(D L P)$ with the DLP-to-dose coefficient associated with the body section of interest in the examination, $k_{\text {exam }}$ (see Supplementary Material Table 1 ), and with the annual frequency of the examination, $f_{\text {exam }}$. Mathematically, this calculation can be described as follows:

$E_{\text {pc,exam }}(E)=\frac{D_{\text {exam }}\left(D L P * k_{\text {exam }} * f_{\text {exam }}\right)}{k_{\text {exam }} * f_{\text {exam }}}$

Finally, the per capita effective dose distribution due to all examinations $E_{p c \text {, all }}(E)$ is the sum of the per capita effective dose distribution of each examination $E_{p c \text {, exam }}(E)$. Since this sum deals with statistical distributions (in other words is the sum of continuous random variables), the result is obtained operatively by performing a mathematical procedure called convolution, which combines sequentially each $E_{p c \text {, exam }}(E)$ distribution as follows:

$E_{p c, \text { sum } 1}(E)=\int_{0}^{E m a x} E_{p c, \text { abdomen }}(E) * E_{p c, \text { chest }}(E-\tau) d \tau$

which calculates the per capita effective dose distribution associated with the sum of abdomen and chest examinations,

$E_{p c, \text { sum } 2}(E)=\int_{0}^{E m a x} E_{p c, s u m 1}(E) * E_{p c, h e a d}(E-\tau) d \tau$

which includes in the per capita effective dose distribution the contribution of head examinations, and

$E_{p c, \text { all }}(E)=\int_{0}^{E m a x} E_{p c, \text { sum } 2}(E) * E_{p c \text { spine }}(E-\tau) d \tau$

that finally gives the per capita effective dose distribution due to all examinations considered.

\section{Results}

\section{Patients of all ages (ages $0-100$ years)}

The total number of CT examinations increased by $43 \%$ from approximately 700,000 in 2004 to over 1 million in 2014, while the relative number of CT scans increased $39 \%$ (from 75 examinations per 1,000 residents in 2004 to 104 in 2014), which corresponds to an average annual increase of $3.5 \%$. The percentage weight of emergency activity has increased from $9.5 \%$ to $22.6 \%$ among the overall CT procedures.

A detailed analysis of CT use by referring to the different body sections involved in the procedures provided the following results. 
- Emergency setting. Head CT examination is the most relevant procedure. In particular, skull CTs cover approximately $70 \%$ of the overall amount. The annual trend of CT examinations classified by anatomical section is shown in Fig. 1A (left), and the relative weight of each section in 2004 and 2014 is reported in Fig. 1A (right). The number of emergency head CTs over the observed length of time tripled (from six to 18 examinations per 1,000 residents). A growth trend can also be observed for facial, abdomen, chest, spine and arthro, albeit with lower numerical importance (fewer than two examinations per 1,000 residents).

- Outpatient setting. Fig. 1B (left) shows an $18.9 \%$ increase in the total number of CT scans per resident. The slight change in the global CT scan number is the result of opposing trends. In fact, while the spine and arthro groups exhibit a reduction of approximately $64 \%$ and $35 \%$, respectively, the trunk and head groups significantly increased. As a result, the percentage weights of the number of arthro CTs and, especially, of spine CTs, were strongly reduced from 2004 to 2014 in favour of trunk and head CT scans (Fig. 1B, right). Data were also processed by classifying CT examinations according to each body region and by calculating the ratio between the number of examinations performed each year normalized to 2004 (Fig. 1C). The largest relative increment was found for neck, chest and abdomen CTs, which were more than doubled in 2014 compared to 2004. Additionally, dental CT scans had significant growth until 2010, which was followed by a decreasing trend. The spine is the anatomical region with the most pronounced reduction.

\section{Paediatric patients (ages $0-17$ years)}

Over the 11-year period, approximately 1.6 million paediatric enrolees underwent a total of $128,563 \mathrm{CT}$ examinations at more than 400 facilities. The total number of CT scans increased by 60 $\%$ from approximately 9,000 in 2004 to 14,400 in 2014, with a variation from 6.3 to 8.5 examinations per 1,000 residents (more than $35 \%$ ), which was mainly due to the positive trend of emergency procedures. The percentage weight of CT scans performed on children in the emergency setting increased from approximately $25 \%$ to $38 \%$ of the total number of CTs.

Data collected in the RHCS allowed for reconstruction of the detailed statistics of CT use relative to the different body sections.

- Emergency setting. As observed in Fig. 1, the main procedure in the emergency setting was a head CT (Fig. 2A). Skull CT, in particular, accounted for more than $69 \%$ of the total examinations performed in the emergency setting in 2014, which increased approximately $70 \%$ compared to 2004. The increase in the trunk, spine and arthro CTs from 2004 to 2014 can be considered irrelevant due to the low number of examinations performed.

- Outpatient setting. The trend of total number of outpatient examinations in paediatrics was almost constant between 2004 and 2014 (Fig. 2B, left). This behaviour is due to a balance between an increase in head and trunk CTs and a decrease in spine and arthro CTs. The time evolution of each type of CT examination compared to 2004 is shown in Fig. 2C. Neck CT data were omitted because of their very low values and associated large numerical fluctuations. The largest relative increment is observed for dental CT scans (from 0.37 to 1.66 examinations per 1,000 residents aged 0-17 years). Additionally, chest and abdomen CTs showed significant growth, while skull, arthro and spine CTs decreased (Fig. 2B).

Dental and facial CTs were the procedures with the highest recurrence rate in 2014.

\section{CT use by age at radiation exposure}

The age distributions of the total number of $\mathrm{CT}$ examinations per resident were calculated for procedures performed in 2004 (blue line) and 2014 (red line) in both emergency care services (Fig. 3, A) and outpatients (Fig. 3, B). The results have similarities; there were negligible values for children younger than 10 years of age, a sharp increase between 10 and 20 years and a plateau above 20 years. Large fluctuations at an age older than 85 years are due to both demographic and RHCS data statistics, while narrow peaks result from rapid demographic changes during or immediately after the first and second world wars.

The impact of CT use in the emergency setting was increased for all ages (Fig. 3A). Those who were 65-100 years of age underwent the highest number of $\mathrm{CT}$ scans, especially in recent years (2014), with values ranging from 20 to 120 examinations per 1,000 residents. In the outpatient care setting, the distribution shifts towards higher ages and the number of CT examinations per resident slightly decreases in the 20- to 55-year age range, while it dramatically increases for the over 65 years group (Fig. 3B). Figure 3 (C, D, E and F) shows the distribution of skull CTs in the emergency care setting and that of dental, chest and abdomen CTs in the outpatient care setting. The most peculiar data were the distribution of dental CTs (Fig. 3D), which showed a large change over time in both the values and the profile.

\section{Population radiation dose due to $\mathrm{CT}$ examinations}

The per capita effective dose calculation is pivotal for fully assessing the impact of radiation exposure associated with CT examinations on the population. Although the assessment over the observation period was based on average values, it 
Fig. 1 Emergency CT (a) and outpatient CT (b) procedures performed from 2004 and 2014 in Lombardy. The results are divided into four macro groups, as described in the Methods session. The number of CT scans per resident (left) and the relative contribution of each group in 2004 and 2014 (right) are shown. Outpatient CT procedures performed between 2004 and 2014 in Lombardy (c) are shown with the relative ratio in the number of each CT examination type performed between 2004 and 2014 compared to in 2004. The CT examinations are classified according to the involved body section
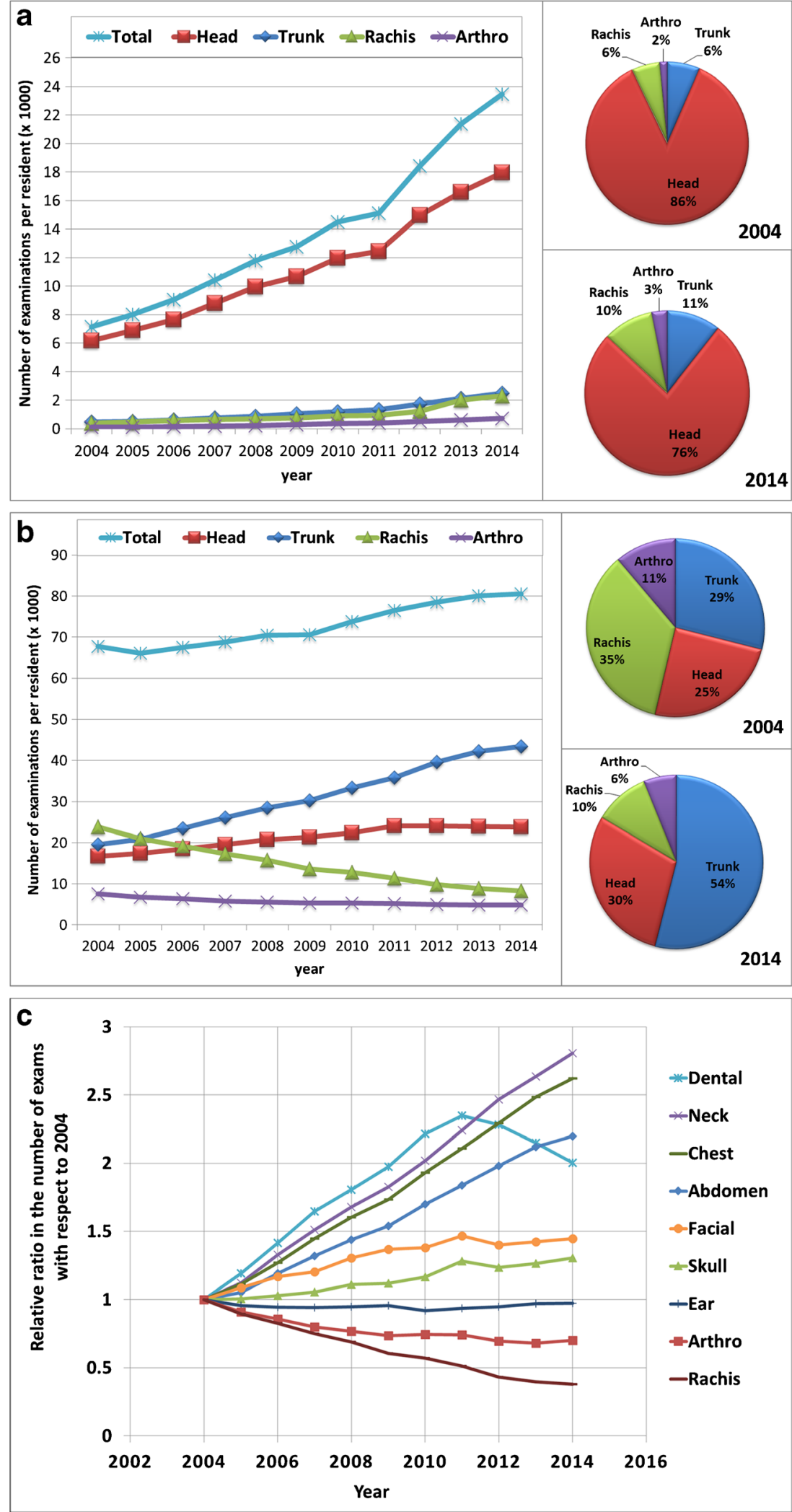

allows for comparison with data in the literature on medical radiation exposure reported for other countries. It should be underlined that this analysis does not consider CT procedures performed during hospitalization (internal examinations); therefore, the dosimetric assessment is likely to underestimate the true total dose value. 
Fig. 2 Emergency paediatric CT procedures (a) and outpatient paediatric $\mathrm{CT}$ procedures (b) performed from 2004 and 2014 in Lombardy. The results are divided into four macro groups as described in the Methods section. The number of CT scans per inhabitant (left) and relative contribution of each group in 2004 and 2014 (right) are shown. Outpatient paediatric CT procedures performed from 2004 and 2014 in Lombardy (c) are shown with the relative ratio of the number of each type of CT examination performed between 2004 and 2014 compared to in 2004. The CT examinations are classified according to the body section involved
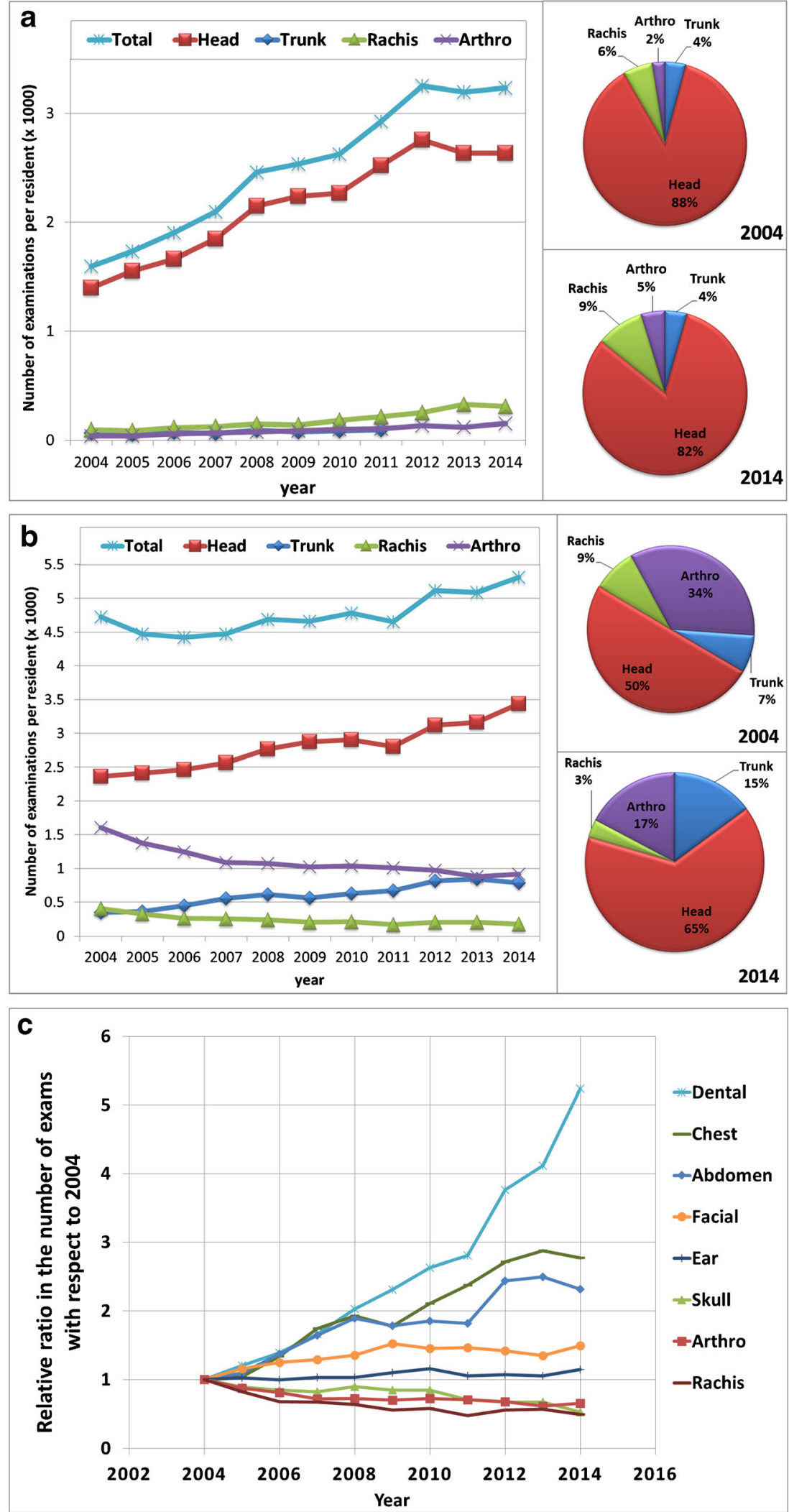

Results obtained according to the procedures described in the Methods section are shown in Fig. 4 (A, B). The mean value of the per capita effective dose increased from $0.72 \mathrm{mSv}$
(2004) to $1.03 \mathrm{mSv}$ (2014) (Fig. 4A) and the related distribution increased (Fig. 4B). This increase in dose, approximately $42 \%$, is directly related to the increased number of CT 
examinations because the dosimetric value (DLP) for each type of examination used for its calculation was kept constant. This assumption could introduce an overestimation in the calculated increment in dose, since the diffusion of modern dose reduction techniques over the study period, such as tube current modulation and iterative reconstruction algorithms, could partially compensate the observed trend. However, this consideration cannot be confirmed and implemented in the calculation, due to the lack of scientifically proven data about the actual trend of DLP values over the study period.

The population fraction exposed to an annual dose higher than $1 \mathrm{mSv}$ increased from $16 \%$ in 2004 to $48 \%$ in 2014. This result alters the range of per capita doses reported from other European national surveys.

\section{Discussion}

\section{General considerations}

This study demonstrates that over a recent 11-year period, there was a general increase in the total number of CT examinations in a large area of Western Europe, where the state-of-the-art medical practice is mostly determined by the public health system control and financing. The increase in the total number of CT scans agrees with the trend reported by similar surveys in other Western areas with health systems that rely on both public and private settings $[3,7,11,12,16]$. With some exceptions (spine, arthro section), all types of $\mathrm{CT}$ procedures performed in the outpatient and emergency-care settings increased from moderate (skull and facial) to remarkable (chest, abdomen, neck and dental).

Because the possibility of a general higher incidence of diseases is an unlikely explanation, possible alternative reasons could be the following.

1. An enhanced trend towards a more defensive medicine attitude, especially when the remarkable increase of some type of emergency medicine investigations is considered, which has very likely affected the head CT pool at any age.

2. The often-overemphasized role of imaging with respect to the clinical examination to reach a correct diagnosis. This could have influenced the increase in abdominal and chest examinations.

3. The use of CT for early lung cancer screening that started in 2000 is one of the reasons for an increase in chest CTs.

4. The observation that $\mathrm{CT}$ procedures are becoming increasingly simple to perform from a technical point of view because of faster scanners and more intuitive software; meanwhile, MR imaging, an alternative to CT in many instances, still suffers from less straightforward application, requiring more advanced and longer staff training. However, this limitation seems to have been overcome in those fields in which CT accuracy is clearly inferior (i.e. arthro and spine investigations). Our data show a steady decrease in the number of CTs in such anatomical sections.

5. The longer survival time of oncological patients who often undergo long-lasting imaging follow-up, which could help explain the remarkable increase in chest and abdominal examinations that we observed in the sixth and seventh decades.

One of the main issues demonstrated in this study is related to the remarkable increase in dental CT examinations in outpatient care around the third and sixth decades (Fig. 3D). This issue needs to be carefully addressed both in term of causative factors and the concern about radiation exposure. It could, for instance, be related to the increase in dental implant procedures, which often require a pre-implant CT map.

The trend of a relative dental-CT decrease shown by Fig. $1 \mathrm{C}$ after 2010 could be explained by the progressive increase in dental examinations based on cone-beam technology in the adult population in lieu of CT.

An increase in the per capita effective dose values, consistent with those reported from other European national surveys, was observed [3,11, 17]. It is known that one-third of medical imaging examinations are not strictly justified by clinical indications [32-37].

\section{Paediatric and teenager population}

One of the most relevant observations regarding paediatric and teenager patients is represented by the remarkable increase in the number of head scans (Fig. 3A and 3B). This result raises some concerns. While the increase in the emergency setting could be partially justified, the increase in outpatient procedures can hardly be acceptable given the large availability of MR units in Lombardy. Of note, the increase in emergency department examinations could be related to a weak conduct compliance performed by health professionals with regard to the head trauma protocol and guidelines in use, which would account mainly for general hospitals. In disagreement with such guidelines and unlike paediatric hospital practice, the use of clinical observation after minor head trauma in the hospital setting might have been wrongly substituted by CT examinations. Regarding the outpatient setting, a decrease in CTs would be expected in favour of MR investigations. As this was not the case, additional reasons could be investigated, such as the insufficient update of general practitioners and family paediatricians. In this regard, it is worth underscoring a relevant feature that has not been addressed by previous similar surveys, which is that the overall increase of head CT examinations over time was remarkable in teenagers and in the middle-aged population (Fig. 3C). While infants and children underwent $\mathrm{CT}$ less frequently, the rates in teenagers were similar to those in adults. This suggests that the concern about exposing a teenager to radiation in clinical 

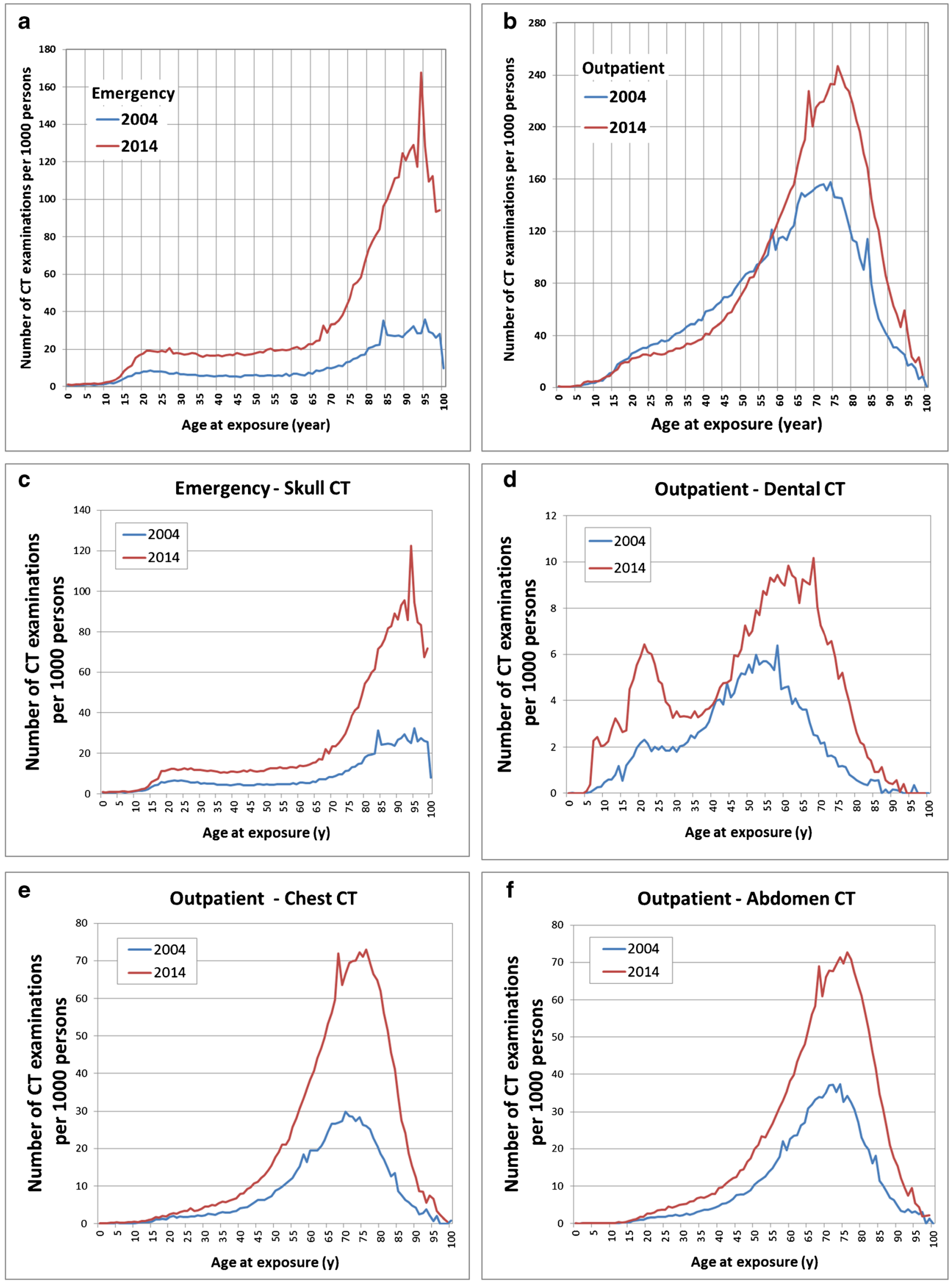
Fig. 3 Distribution of the number of CT scans per person at different ages at exposure performed in 2004 and 2014 in the emergency (a) and outpatient (b) settings. The number of CT scans per resident at different ages at exposure performed in 2004 and 2014 for the following most important CT procedures are shown: skull in the emergency setting (c) and dental (d), chest (e) and abdomen (f) in the outpatient setting

practice is frequently similar to that in adults. However, teenagers, albeit less prone to radiation-induced cancer than infants, have a higher risk from CT exposure than adults. This hypothesis is supported by the observation that a significant percentage of physicians still underestimate the radiation dose from CT scans [38-50].

\section{Paediatric and teenager dental radiation exposure}

Dental CTs had the highest relative increase over time compared to all other procedures with an almost fivefold increase (Fig. 2C). Unlike the older age groups, where dental implant procedures could explain the increase in CT examinations [51], the increase for the younger age group is more difficult to explain:
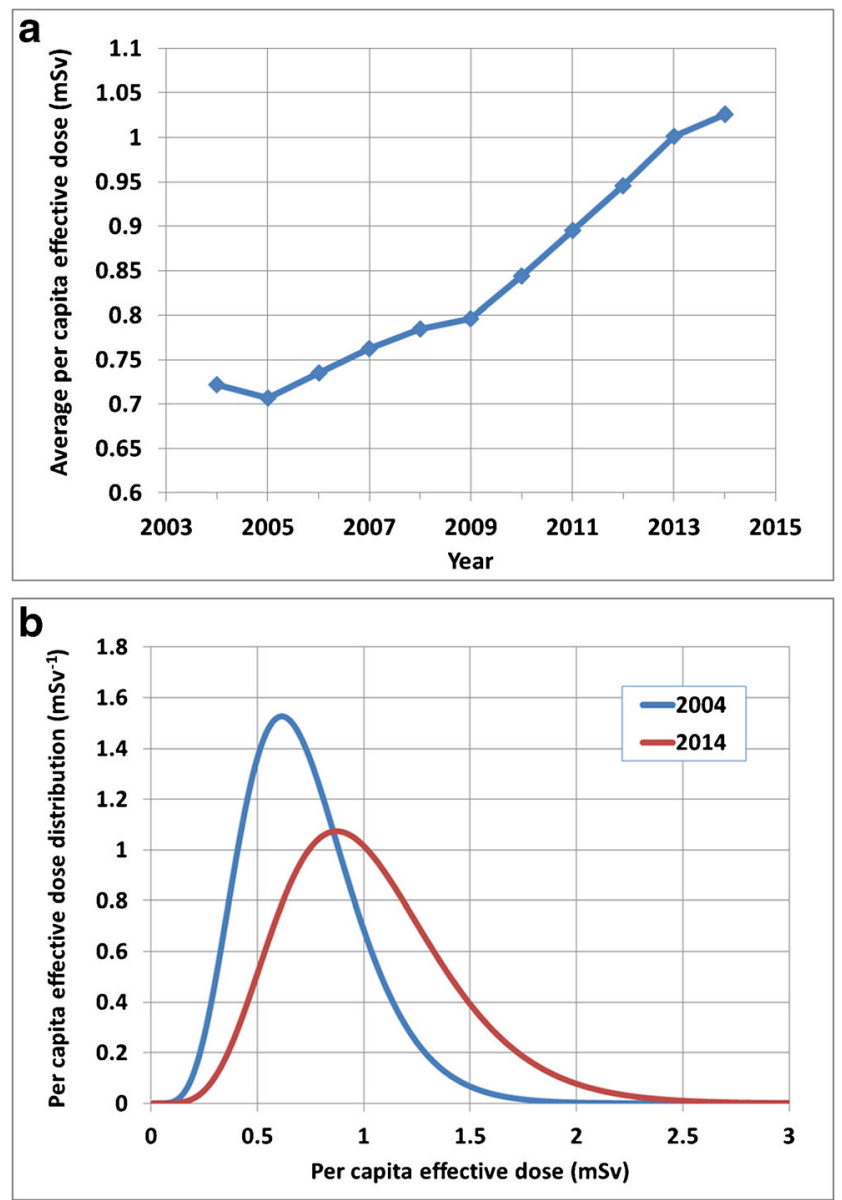

Fig. 4 (a) Trend of the mean value of the per capita effective dose from 2004 to 2014. (b) Distribution of the per capita effective dose due to all CT procedures $\left(E_{p c \text {, all }}(E)\right.$ in the text) performed in Lombardy in 2004 (blue line) and 2014 (red line)
1. In recent years, paediatric oral surgeons, dentists and orthodontists have expanded the number of complex procedures that require detailed pre-treatment imaging.

2. There is a lack of guidelines in paediatric dental radiology in our country for the considered time span [52], though most recently published new guidelines clearly exclude the routine use of dental CTs in children except in exceptional and very complex circumstances [53].

3. There has been an increase in private paediatric dental care centres in Lombardy in recent decades, which may have triggered a trend towards increasing highly remunerative procedures, such as dental CTs. It also must be considered that CT technology is a major investment for the private sector that needs to be reimbursed.

\section{Conclusions}

The increase in CT use and in the CT-derived radiation dose in the population is occurring in spite of the evidence of the substantially improved carcinogenic potential of low doses of X-ray radiation, particularly for children.

In contrast with several published investigations, which underline the radiation risk for paediatric age, the level of detail of the data processed in this study highlights a remarkable increase in the irradiation of teenagers and young adults, whose risk tends to be underestimated.

The fivefold increase in dental CTs over about a decade in the younger age groups raises a special concern and must be addressed by further investigations.

Acknowledgements We thank Dr. Maurizio Bersani from Direzione Generale Sanità, Regione Lombardia, who kindly helped and supported us during the data selection and collection.

\section{Compliance with ethical standards}

Guarantor The scientific guarantor of this publication is Andrea Pola.

Conflict of interest The authors of this manuscript declare no relationships with any companies whose products or services may be related to the subject matter of the article.

Funding This study has received funding by Direzione Generale Sanità, Regione Lombardia, Call per la ricerca indipendente 2010-2013.

Statistics and biometry One of the authors has significant statistical expertise.

Informed consent Written informed consent was not required for this study because no human subjects were involved in this study.

Ethical approval Institutional Review Board approval was not required for this study because no human subjects were involved in this study. 
Methodology

- retrospective

- multicentre study

\section{References}

1. Shannoun F, Zheeb H, Back C, Blettner M (2006) Medical exposure of the population from diagnostic use of ionizing radiation in Luxembourg between 1994 and 2002. Health Phys 91:154-162

2. Brenner DJ, Hall EJ (2007) Computed tomography - An increasing source of radiation exposure. N Engl J Med 357:2277-2284

3. Borretzen I, Lysdahl KB, Olerud HM (2007) Diagnostic radiology in Norway trends in examination frequency and collective effective dose. Radiat Prot Dosim 124:339-347

4. Fazel R, Krumholz HM, Wang Y et al (2009) Exposure to low dose ionizing radiation from medical imaging procedures. $\mathrm{N}$ Engl J Med 361:849-857

5. Catuzzo P, Aimonetto S, Zenone F et al (2010) Population exposure to ionizing radiation from CT examinations in Aosta Valley between 2001 and 2008. Br J Radiol 83:1042-1051

6. Muhogora WE, Ahmed NA, Alsuwaidi JS et al (2010) Paediatric CT examinations in 19 developing countries: frequency and radiation dose. Radiat Prot Dosim 140:49-58

7. Kocher KE, Meurer WJ, Fazel R, Scott PA, Krumholz HM, Nallamothu BK (2011) National trends in use of computed tomography in the emergency department. Ann Emerg Med 58:452-462

8. Pearce MS, Salotti JA, McHugh K et al (2011) CT scans in young people in Northern England: trends and patterns 1993-2002. Pediatr Radiol 41:832-838

9. Guite KM, Hinshaw JL, Ranallo FN, Lindstrom MJ, Lee FT Jr (2011) Ionizing radiation in abdominal CT: unindicated multiphase scans are an important source of medically unnecessary exposure. $\mathrm{J}$ Am Coll Radiol 8:756-761

10. Bernier M-O, Rehel JL, Brisse HJ et al (2012) Radiation exposure from CT in early childhood: a French large-scale multicenter study. Br J Radiol 85:53-60

11. Samara ET, Aroua A, Bochud FO et al (2012) Exposure of the Swiss population by medical x-rays: 2008 review. Health Phys 102(3):263-270

12. Smith-Bindman R, Miglioretti DL, Johnson E et al (2012) Use of diagnostic imaging studies and associated radiation exposure for patients enrolled in large integrated health care systems, 19962010. JAMA 307:2400-2409

13. Aroua A, Samara ET, Bochud FO, Meuli R, Verdun FR (2013) Exposure of the Swiss population to computed tomography. BMC Med Imaging 13:22

14. Hayton A, Wallace A, Marks P, Edmonds K, Tingey D, Johnston P (2013) Australian per caput dose from diagnostic imaging and nuclear medicine. Radiat Prot Dosim 156:445-450

15. Etard C, Aubert B, Mezzarobba M, Bernier MO (2014) Exposure of the French paediatric population to ionizing radiation from diagnostic medical procedures in 2010. Pediatr radiol 44:1588-1594

16. Le Coultre R, Bize J, Champendal M et al (2015) Exposure of the Swiss population by radiodiagnostics: 2013 review. Radiat Prot Dosim. https://doi.org/10.1186/1471-2342-13-22

17. HPA-CRCE-012 (2008) Frequency and collective dose for medical and dental X-ray examinations in the UK. HPA-CRCE-012. Available via https://www.gov.uk/government/uploads/system/ uploads/attachment data/file/340154/HPA-CRCE-012 for website.pdf

18. Institut de Radioprotection et de Sureté Nucléaire (2014). Exposition de la population francaise aux rayonnements ionisants liée aux actes de diagnostic médical en 2012. Institut de
Radioprotection et de Sureté Nucléaire, Fontenay-aux-Roses. Available via http://www.eurosafeimaging.org/wp/wp-content/ uploads/2015/05/IRSN-PRP-HOM-2014-6_Exposition-Francerayonnements-diagnostic-medical-2012.pdf

19. United Nations Scientific Committee on the Effects of Atomic Radiation (2010) UNSCEAR 2008 report Vol 1: Sources of ionizing radiation. United Nations, New York Available via http://www.unscear.org/docs/ reports/2008/09-86753 Report 2008 Annex B.pdf

20. International Commission on Radiological Protection (2007) Radiological protection in medicine, 105. Annals of the ICRP 37(6): $1-332$

21. Committee on the Biological Effects of Ionizing Radiation (2006) Health Risks from Exposure to low Levels of Ionizing Radiation (BEIR VII), National Academy of Sciences, National Research Council. National Academy Press, Washington

22. Pearce MS, Salotti JA, Little MP et al (2012) Radiation exposure from CT scans in childhood and subsequent risk of leukaemia and brain tumours: a retrospective cohort study. Lancet 380(9840):499-505

23. Mathews JD, Forsythe AV, Brady $Z$ et al (2013) Cancer risk in 680.000 people exposed to computed tomography scans in childhood or adolescence: data linkage study in 11 million Australians. BMJ. https://doi.org/10.1136/bmj.f2360

24. Berrington de Gonzalez A, Darby S (2004) Risk of cancer from diagnostic X-rays: estimates for UK and 14 other countries. Lancet 363:345-351

25. Brenner DJ, Elliston C, Hall E, Berdon W (2001) Estimated risks of radiation-induced fatal cancer from pediatric CT. AJR Am J Roentgenol 176:289-296

26. Krille L, Zeeb H, Jahnen A et al (2012) Computed tomographies and cancer risk in children: a literature overwiev of CT practices, risk estimations and an epidemiologic cohort study proposal. Radiat Environ Biophys 51:103-111

27. Brady Z, Cain TM, Johnston PN (2011) Paediatric CT imaging trends in Australia. J Med Imaging Radiat Oncol 55:132-142

28. Pearce MS, Salotti JA, Howe NL et al (2012) CT scans in young people in Great Britain: temporal and descriptive patterns, 19932002. Radiol Res Pract 2012:1-8

29. Menoch MJ, Hirsh ADA, Khan NS, Simon HK, Sturm JJ (2012) Trends in computed tomography utilization in the pediatric emergency department. Pediatrics 129:e690-e697

30. Palorini F, Origgi D, Granata C, Matranga D, Salerno S (2013) Adult exposures from MDCT including multiphase studies: first Italian nationwide survey. Eur Radiol. 44:469-483

31. European Commission (1999) European guidelines on quality criteria for Computed Tomography. EUR 16262. European Commission, Bruxelles Available via http://www.drs.dk/ guidelines/ct/quality/htmlindex.htm

32. International Commission on Radiological Protection (2008) Radiological Protection in Medicine. Pubblication 105. Elsevier, Oxford

33. International Commission on Radiological Protection (2008) Recommendations of the ICRP, Publication 103. Elsevier, Oxford

34. European Commission (2001) Referral Guidelines for Imaging, Radiation Protection 118. Office for Official Publications of the European Communities, Luxembourg

35. EURATOM (2014) Council Directive 2013/59/EURATOM. EURATOM, Bruxelles Available via http://eur-lex.europa.eu/legalcontent/EN/ALL/?uri=OJ\%3AL\%3A2014\%3A013\%3ATOC

36. Malone J, Guleria R, Craven C et al (2012) Justification of diagnostic medical exposures: some practical issues. Report of an International Atomic Energy Agency Consultation. Br J Radiol 85:523-538

37. Rehani MM, Berris T (2012) International Atomic Energy Agency study with referral physicians on patient radiation exposure and its tracking: a prospective survey using a web-based questionnaire. BMJ Open. https://doi.org/10.1136/bmjopen-2012 
38. Mola E, Visentin G, Elli P, Orlando T (2012) Valutazione dei Bisogni Formativi dei Medici Prescrittori in Merito al Rischio da Radiazioni Ionizzanti. Available via http:/www.occhioclinico.it/ cms/node/1375

39. Borgen L, Stranden E, Espeland A (2010) Clinicians' justification of imaging: do radiation issues play a role? Insights Imaging 1:193-200

40. O'Sullivan J, O'Connor OJ, O'Regan K et al (2010) An assessment of medical students awareness of radiation exposures associated with diagnostic imaging investigations. Insights Imaging 1:86-92

41. Lee C, Haims AH, Monico EP, Brink JA, Forman HP (2004) Diagnostic CT scans: assessment of patient, physician, and radiologist awareness of radiation dose and possible risks. Radiology 231:393-398

42. Thomas KE, Parnell-Parmley JE, Haidar S et al (2006) Assessment of radiation dose awareness among pediatricians. Paediatr Radiol 36:823-832

43. Heyer CM, Hansmann J, Peters SA, Lemburg SP (2010) Paediatricians awareness of radiation dose and inherent risk in chest imaging studies- A questionnaire study. Eur J Radiol 76: 288-293

44. Shiralkar S, Rennie A, Snow M, Galland RB, Lewis MH, GowerThomas K (2003) Doctors' knowledge of radiation exposure: questionnaire study. BMJ 327:371-372

45. Jacob K, Vivian G, Steel JR (2004) X-ray dose training: are we exposed to enough? Clin Radiol 59:928-934

46. Arslanoglu A, Bilgin S, Kubal Z, Ceyhan MN, Ilhan MN, Maral I (2007) Doctors and intern doctors' knowledge about patients' ionizing radiation exposure doses during common radiological examinations. Diagn Interv Radiol 13:53-55

47. Bautista AB, Burgos A, Nickel BJ et al (2009) Do clinicians use the American College of Radiology Appropriateness Criteria in the Management of their patients? AJR Am J Roentgenol 192:1581-1585

48. Soye JA, Paterson A (2008) A survey of awareness of radiation dose among health professionals in Northern Ireland. Br J Radiol $81: 725-729$

49. Picano E (2004) Informed consent and communication of risk from radiological and nuclear medicine examinations: how to escape from a communication inferno. BMJ 329:849-851

50. Picano E (2004) Sustainability of medical imaging. BMJ 328:578-580

51. Bornstein MM, Scarfe WC, Vaughn VM, Jacobs R (2014) Cone beam computed tomography in implant dentistry: a systematic review focusing on guidelines, indications, and radiation dose risks. Int J Oral Maxillofac. Implants. https://doi.org/10.11607/jomi. 2014suppl.g1.4

52. European Commission (2004) European guidelines on radiation protection in dental radiology. Rp 136, European Commission, Publication Office, Luxembourg. Available via https://ec.europa. eu/energy/sites/ener/files/documents/136.pdf

53. European Commission (2011) SEDENTEXCT project Radiation protection n. 172: Cone Beam CT for dental and maxillofacial radiology (Evidence based guidelines). European Commission, Publication Office, Luxembourg Available via http://www. sedentexct.eu/files/radiation protection 172.pdf 